\title{
Impactos socioculturales del turismo. Dimensiones conceptuales, teóricas y empíricas \\ México: Trillas
}

Alfonso González Damián

Universidad de Quintana Roo

Unidad Académica Cozumel gonzalezd@uqroo.edu.mx

U na de las preocupaciones que con el tiempo ha ido ganando atención respecto al desarrollo acelerado del turismo en el mundo es la de sus impactos socioculturales en el ámbito de las sociedades receptoras del turismo, pero también de aquellos que suceden en las sociedades emisoras de turistas, tras la realización de sus viajes. La preocupación surgió desde hace más de cuatro décadas, con la realización y publicación de profusos estudios sobre los impactos socioculturales, al grado de considerarse uno de los temas más trabajados en los estudios turísticos (Deery et al., 2012), lo que no es de sorprenderse puesto que estos impactos son, entre los distintos que acontecen al turismo, los que más atentan contra la sostenibilidad del desarrollo turístico, y que no obstante, son los menos comprendidos. Monterrubio en su obra, Impactos socioculturales del turismo publicada por Trillas (2018), argumenta, con mucha razón, que si bien los estudios en la temática resultan prolíficos, en una revisión profunda, no abundan entre ellos los que se sustenten en una argumentación teórica sólida que permita no solo saber qué impactos propicia el turismo sino por qué y cómo suceden tales impactos, los factores que los propician, lo que permitiría eventualmente servir como antecedente para que se puedan mitigar, contrarrestar, limitar o evitar.

La obra se posiciona en este punto como una plataforma de partida, auténtica base conceptual para que los estudios de los impactos socioculturales del turismo sean comprendidos de manera articulada y tendiente hacia una mayor y mejor comprensión teórica y empírica de su devenir. En opinión del que suscribe, la obra está destinada a posicionarse como libro básico, texto guía o básico para quienes desde el ámbito académico o profesional se interesen en los estudios de los impactos socioculturales del turismo: estudiantes de licenciatura y posgrado, nuevos y consolidados investigadores, grupos de investigación, profesionales y gestores del turismo.

Una de las primeras y más notorias virtudes de la obra consiste en que el autor nos acerca a los textos publicados en lengua inglesa, en la que de manera prolífica se ha 
abordado el tema de los impactos socioculturales del turismo, no necesariamente en el mundo anglosajón, y que a lo largo de los años se ha constituido en la corriente principal en el campo de la temática y que no siempre se encuentran accesibles para el hispanoparlante, tanto por las limitaciones lingüísticas como por tratarse en muchos casos de documentos accesibles mediante pago o suscripción. Además de identificar y analizar los principales textos y sus modelos y conceptos, el autor los presenta de manera ordenada, no sólo desde un punto de vista puramente cronológico, sino desde una lógica que bien puede calificarse de antecedente hacia una clasificación teórica o metaconceptual de los productos analizados.

El libro se integra de seis partes: cuatro partes conceptuales, una teórica y una parte final empírica. Las cuatro primeras conceptualizan la evaluación de impactos sociales, de impactos del turismo, los de tipo sociocultural en ese ámbito, así como las características que presentan. La parte teórica se divide en dos apartados, uno sobre las teorías elaboradas desde la información empírica y que son ampliamente reconocidas y referidas en la literatura turística, y otro sobre las teorías tomadas de diversas disciplinas y que se han utilizado con mayor o menor éxito para entender los impactos socioculturales del turismo. Finalmente la parte empírica presenta cuatro casos específicos estudiados por el propio autor.

La noción de impacto como tal surge de la idea de desarrollo. Se sabe que todo proyecto de desarrollo generará cambios en las sociedades, algunos de los cuales podrían considerarse benéficos, pero otros serán perjudiciales para distintos grupos, segmentos o capas de la población. En tal sentido, estos cambios, entendidos como impactos de los proyectos de desarrollo, requieren ser identificados, entendidos, evaluados y monitoreados, antes, durante y a lo largo de la implementación de cualquier proyecto, de los que sin duda no escapan los proyectos turísticos. Desde los primeros estudios sobre el tema en cuestión, se ha enfatizado en los impactos que la actividad produce en los sitios de destino, y se ha clasificado a los impactos en tres grandes bloques: económicos, socioculturales y naturales, en los que afecta la vida individual y colectiva de los miembros de poblaciones locales. El enfoque que ha prevalecido en la concepción de tales impactos, se ha centrado en la valoración de sus beneficios y costos, así como en su posible evaluación.

Los impactos del bloque sociocultural, o más propiamente para el autor, los impactos socioculturales del turismo, no solo se presentan en los habitantes locales en los sitios de destino turístico, sino también en los turistas que les visitan, aunque la literatura académica se ha volcado mayoritariamente en el análisis de los impactos en las poblaciones receptoras de turismo. Al respecto, el autor nos llama a la reflexión respecto a que los temas no solo deberían definirse desde lo que dice la literatura, sino a partir de las condiciones socioeconómicas y culturales específicas de cada destino turístico, a partir del estudio de las percepciones y actitudes de los residentes hacia el turismo y también de las de los turistas hacia sus viajes.

En la obra, el autor clasifica a los impactos socioculturales del turismo con base en distintos atributos que han sido señalados en la literatura académica, que los hacen ser 
tangibles e intangibles; macro, meso y micro; individuales y colectivos; directos e indirectos; positivos y negativos; planeados, no planeados y multiplicadores; a corto, mediano y largo plazo. Algunos factores de alta relevancia para determinar el tipo y magnitud de los impactos del turismo mencionados por el autor son: modalidad turística, número de turistas, comportamiento de los turistas, etapa del ciclo de vida del destino, diferencia económica entre locales y turistas, diferencia cultural entre locales y turistas, papel de los intermediarios, nivel de participación local, estacionalidad turística, otros agentes de cambio. En conjunto estos factores aceleran, maximizan, disminuyen o agudizan los cambios inducidos por el turismo.

Si bien, el autor señala que los estudios sobre los impactos socioculturales del turismo se han caracterizado por su falta de fundamentación teórica y conceptual, esto no significa que no existan esfuerzos encomiables y que se han tornado en modelos ejemplares en la literatura especializada; es el caso de las propuestas que el autor denomina "modelos teóricos del turismo": la matriz de actitudes y comportamiento hacia el turismo de Butler (1980); el índice de irritación turística de Doxey (1975); el ciclo de vida de un área turística de Butler (1980); las estrategias culturales de enfrentamiento local de Dogan (1989); el continuo de estrategias de adopción -retirada de Ap y Crompton-. Asimismo, el autor menciona otras teorías desarrolladas en diversas disciplinas o campos del conocimiento que se han aplicado para la explicación de los impactos del turismo: teoría del intercambio social, teoría de las representaciones sociales, teoría de la amenaza integrada, teoría de la identidad social y teoría de la identidad con el lugar.

En la parte final, el autor presenta el análisis de cuatro casos de estudio con su abordaje metodológico y conceptual, así como perspectivas teóricas adecuadas a la necesidad o particularidad de cada uno de los casos: 1) Estereotipos, turistas y actitudes de prestadores de servicios turísticos en Huatulco, México; 2) Spring break y actitudes locales en Acapulco, México; 3) Turismo nudista y estigmatización, en Zipolite, México; y 4) Turismo y la máscara Boruca, en el sur de Costa Rica.

A manera de reflexión final, se puede afirmar que el estudio de los impactos socioculturales del turismo se encuentra aún en desarrollo y si bien muchos de los trabajos producidos en la literatura especializada se caracterizan por ser exploratorios y descriptivos, el analizar en profundidad sus causas y procesos es un reto que bien puede encontrar bases en trabajos comprensivos e integradores como el que nos entrega Monterrubio. Durante años. la industria del turismo internacional no se preocupó por los aspectos socioculturales, pero hoy, con el auge de los nuevos turismos, como el ecoturismo o el turismo cultural que poco a poco pero inexorablemente van ganando presencia frente al turismo convencional masificado, comienza a darse cuenta de que corre el riesgo de acabar con el cuerno de la abundancia, si no es que ya lo hizo antes, al afectar las costumbres, las tradiciones, la cultura y en general a las sociedades tanto receptoras como emisoras.

Muy particularmente, para quienes formamos parte de las sociedades receptoras de turismo, nos encontramos día a día con el hecho de que por la presencia y desarrollo del turismo, nuestro mismo entorno, la sociedad, la economía y la vida en general son 
impactados en mayor o menor medida. Si deseamos que la actividad turística nos beneficie pero a la vez que no nos sobrepase, que no nos excluya ni nos despoje, que nos permita avanzar hacia un desarrollo sostenible, necesitamos entender cómo se producen los impactos socioculturales, cómo se construyen, cómo se relacionan entre ellos y por qué; es decir, necesitamos estudiarlos con bases más sólidas, bases a las que contribuyen obras como la de Monterrubio Cordero.

\section{Referencias}

Ap, J., y Crompton, J. L. (1993). Residents' Strategies for Responding to Tourism Impacts. Journal of Trave/ Research, 32(1), 47-50. https://doi.org/https://doi.org/10.117 7\%2F004728759303200108

Butler, R. W. (1980). The concept of a tourist area cycle of evolution: implications for management of resources. The Canadian Geographer/Le Géographe Canadien, 24(1), 5-12.

Deery, M., Jago, L., y Fredline, L. (2012). Rethinking social impacts of tourism research: A new research agenda. Tourism Management, 33(1), 64-73. https://doi.org/10.1016/j.tourman.2011.01.026

Doğan; H. Z. (1989). Forms of adjustment. Sociocultural impacts of tourism. Annals of Tourism Research; 16(2); 216-236. https://doi.org/10.1016/0160-7383(89)90069-8

Doxey, G. (1975). A causation theory of visitor-resident irritants: Methodology and research inferences. En The impact of tourism, Sixth Annual Conference Procedures of the Travel Research Association.

Monterrubio Cordero, J. C. (2018). Impactos socioculturales del turismo. Dimensiones conceptuales, teóricas y empíricas. México: Trillas. 